\title{
Determination of the Total Water Vapour Content of Sokoto Area Atmosphere
}

\author{
${ }^{*}$ M. B. Abdullahi, ${ }_{* * *}^{*}$ U. Zangina, ${ }^{* * *}$ M. I. Ilyasu, *D. O. Akpootu \\ M. Sulaiman and $*$ S. Abdullahi \\ * Dep't of Physics, Usmanu Danfodiyo University Sokoto \\ ** Sokoto Energy Research Centre, UDU Sokoto \\ ***Physics Unit, Sokoto Polytechnic
}

\begin{abstract}
A study was carried out to estimate the quantity of total water vapour content of the atmosphere for Sokoto area using solar radiation intensity measurements. Pyronometerwas used to record solar intensities for the month of September, 2012 on daily basis extending from 8.00 hour to 17.00 hour local time. Red and blue plastic filters were used in taking separate measurements of solar intensities in addition to no filter measurements. Total water vapour content was determined using ELSSASER square approximations law. Results indicated that highest value of water vapour content of the atmosphere of $1.458 \mathrm{Kgm}^{-2}$ was recorded on the $20^{\text {th }}$ day of the month while the least value of $0.937 \mathrm{Kgm}^{-2}$ was obtained on the $22^{\text {nd }}$ day of the month. Average water vapour content for the study area was found to be $1.243 \mathrm{Kgm}^{-2}$. The procedure involved in this method gives similar result as the conventional methods used for estimating atmospheric water vapour content and the subsequent relative humidity for the study area.
\end{abstract}

\section{Introduction}

The solar radiation available on the surface of the earth is less than the radiation available outside the earth's atmosphere and this reduction in intensity is dependent on the atmospheric conditions such as amount of dust particles, water vapour, ozone content etc and solar altitude. The number of photons ateachenergy is reduced upon entering the earth's atmosphere due to reflection, to scattering or to absorption by dust particles, water vapour and other gases. (Garg, 1982).Radiation coming from the sun and re-emitted by the earth hitsmolecules in the air. If the energy of this radiation matches the energy necessary to create particular oscillations of the molecules (to "excite" them), the radiation energy is taken up (=absorbed) and stored in the air itself. (Elma, 2001). The water vapour content of air is highly variable and depends strongly on air temperature. Cold air is very dry (polar air, for example) and cannot hold much moisture, whereas warm air can hold a much larger amount (as in tropical air). In warm regions, however, the relative humidity can vary between $0 \%$ and $100 \%$ (deserts vs. rain forest). Because of the strong variation depending on location and altitude, and the influence of water on the climate, it is very hard to forecast the climate in a reliable way (Susanne, 2001). Due to the so called "greenhouse effect" - caused by atmospheric trace gases such as carbon dioxide $\left(\mathrm{CO}_{2}\right)$, ozone $\left(\mathrm{O}_{3}\right)$, and water vapour $\left(\mathrm{H}_{2} \mathrm{O}\right)$ - infrared radiation from the earth is stored temporarily in the atmosphere. Of all these trace gases, water vapour represents the most important constituent. It contributes to the natural greenhouse warming process by approximately $60 \%$. Water vapour amplifies the anthropogenic contribution to greenhouse warming through a positive feedback. This amplification is counteracted by the increased reflection off clouds. How these two factors combine in the real atmosphere still remains an open question.(Elmar, 2001). The quantity of water vapour present in the atmosphere is of primary importance in weather phenomena. Water vapour can condense into clouds and fogs. Where water vapour is only in small proportions, extremely dry desert may result. The amount of water vapour present in the air is referred to as humidity. The proportion of the amount of water vapour present at a given temperature relative to the maximum quantity that could be present is known as relative humidity (Arthur and Alan, 1997).It is very hard to quantify water vapour in the atmosphere. Its concentration changes continually with time, location and altitude. Meteorologists have long measured water vapour in the air. Every day, standard measurements of temperature, pressure and water vapour concentration are performed. Often balloon sondes are used for these measurements. In this procedure, measurement equipment is attached to a balloon, which is released into the air and rises up to $10 \mathrm{~km}$, all the while measuring a so-called vertical profile of water vapour and other meteorological data above a certain point on the Earth surface and relaying the data via radio back to the surface. The equipment used nowadays on sondes and at the surface is a psychrometer, or a dewpoint meter. Long ago, the meteorologists used a "hair-hygrometer". Degreased hair has the characteristic that its length changes with humidity, and this was used to determine the water content of air! Most of these instruments have to be calibrated. This means that for the case of a hair-hygrometer (hygro is Greek for moisture), the length of a hair has to be measured at an exactly known water vapour concentration in a lab. From this model 
value, the actual value of the concentration in the atmosphere can be calculated if you measure the length of the same hair somewhere else in the atmosphere. Nowadays, much more advanced and precise equipment is used. Even so, scientists are regularly discovering sources of systematic error in these modern measurement techniques (one was recently found of up to $10 \%$ ), due to different conditions during the calibration in the lab and in the real atmosphere, and thus instruments are constantly improving. For this reason, it is important to use as many techniques as possible, in our case to measure the humidity of air. To get a global overview, only satellite measurements are suitable. From a satellite, the absorption of the reflecting sunlight due to water vapour molecules is measured. The results are pictures of global water vapour distributions and their changes. The measurement error, however, is still about 30 to $40 \%$. (Ruediger, 2001). The present study is however, a ground based measurement technique aims at employing solar radiation intensity measurements for the estimation of atmospheric water vapour content of the study area.

\section{Material And Method}

Measurements for the solar radiation intensity were carried out on hourly basis from 8.00 hours to 17.00hours for the month of September, 2012 usingPyronometer. Measurements recorded for the $20^{\text {th }}$ to $23^{\text {rd }}$ September, 2012 were used in this report. For each hour three measurements for solar radiation intensities - with no plastic filter, with red plastic filter and with blue plastic filter - were recorded and tabulated. Natural logarithms of solar radiation intensities due to red and blue components, sun's hourly position and corresponding air mass values were computed and tabulated. For sun's hourly position and air mass values the subsequent equations 1 to 5 were used.

$\cos \theta=\sin \Phi \sin \delta+\cos \Phi \cos \delta \cosh$

Where

$\theta=$ Zenith angle, $\Phi=$ latitude of a place, north or south of the equator

with

north being positive

But

$\delta=$ Declination angle of the sun, $\mathrm{h}=$ Hour angle from the solar noon with morning as positive.

$\delta=23.45 \sin \{360[(284+\mathrm{n}) / 365.25]\}$

$\mathrm{h}=\backslash 12-\mathrm{H} \backslash * 15$

2

Where

$\mathrm{n}=$ number of days of a year, January $1^{\text {st }}$ as day 1.

$\mathrm{H}=$ hour under consideration for solar intensity measurement.

$\mathrm{m}=\left[\{(\mathrm{R} / \mathrm{H}) \cos \theta\}^{2}+2(\mathrm{R} / \mathrm{H})+1\right]^{1 / 2}-(\mathrm{R} / \mathrm{H}) \cos \theta$

(Idemudia,1998).

4

For $\mathrm{R}=6370 \mathrm{Km}$ and $\mathrm{H}=7991 \mathrm{Km}$, the values of air mass $\mathrm{m}$, and $\sec \theta$ are very nearly equal (to 2 decimal places) for angles of $\theta<70^{\circ}$. Thus:

$\mathrm{m}=\sec \theta$

5

(Idemudia, 1998).

From the square root approximation of ELSSASER law, it is required that the optical depth of water which is about $5 \%$ of the total optical depth, $T$ need to be obtained in order to determine the atmospheric water vapour content of a given place.

Beer-Lambert law can be applied to describe the attenuation of solar radiation as it travels through the atmosphere. In this case there is scattering of radiation as well as absorption. The Beer-Lambert law for the atmosphere is usually written as:

$$
\mathrm{I}=\mathrm{I}_{0} \exp \left[-\mathrm{m}\left(\mathrm{T}_{\mathrm{a}}+\mathrm{T}_{\mathrm{g}}+\mathrm{T}_{\mathrm{NO} 2}+\mathrm{T}_{\mathrm{w}}+\mathrm{T}_{\mathrm{O} 3}+\mathrm{T}_{\mathrm{r}}\right)\right]
$$

Where each $T_{x}$ is the optical depth whose subscript identifies the source of the absorption or scattering it describes:

- a refers to aerosols (that absorbs and scatter)

- $\mathrm{g}$ are uniformly mixed gasses

- $\mathrm{NO}_{2}$ is nitrogen dioxide mainly due to urban pollution (absorption)

- $\quad \mathrm{w}$ is the water vapour absorption

- $\mathrm{O}_{3}$ is ozone (absorption only)

- $\mathrm{r}$ is Rayleigh scattering from molecular oxygen and nitrogen.

Therefore:

(Houghton).

$\ln \mathrm{I}=-\mathrm{mT}+\ln \mathrm{I}_{0}$

Straight line graphs of $\ln \mathrm{I}_{R}$ against $\mathrm{m}$ and $\ln _{\mathrm{B}}$ against $\mathrm{m}$ were plotted, slopes were calculated and intercepts determined.The slope of resultant straight line graph of equation 7 would provide the optical depth values needed for the estimation of atmospheric water vapour content of the study area. The daily atmospheric water 
vapour content of the atmosphere was determined using the square approximation of ELSASSER law given by equation 8 .

Where:

$$
\mathrm{U}=\left[\mathrm{T}_{\mathrm{R}} / \mathrm{T}_{\mathrm{B}}\right]^{2}
$$

$\mathrm{U}=$ Atmospheric water vapour content, $\mathrm{T}_{\mathrm{R}}=$ Slope of the graph of $\ln \mathrm{I}_{\mathrm{R}}$ against $\mathrm{m}$ and $\mathrm{T}_{\mathrm{B}}=$ Slope of the graph of $\ln \mathrm{I}_{\mathrm{B}}$ against $\mathrm{m}$.

\section{Results And Graphs}

Readings obtained and computed values are presented in table 1.

\begin{tabular}{|c|c|c|c|c|c|c|c|}
\hline \multicolumn{4}{|c|}{$\begin{array}{l}\text { Date: } 20^{\text {th }} \text { November, } 2012 \text {. } \\
\text { Time/hrlnI } \mathrm{R}_{\mathrm{R}} \ln _{\mathrm{B}} \quad \text { air mass, } \mathrm{m}\end{array}$} & \multicolumn{4}{|c|}{$\begin{array}{l}\text { Date: } 22^{\text {nd }} \text { November, } 2012 . \\
\text { Time } / \text { hrlnI }_{R} \operatorname{lnI}_{B} \quad \text { air mass, } m\end{array}$} \\
\hline 08.00 & 4.01 & 3.69 & 2.05 & 08.00 & 4.17 & 3.81 & 2.07 \\
\hline 09.00 & 4.61 & 4.01 & 1.45 & 09.00 & 4.74 & 4.38 & 1.46 \\
\hline 10.00 & 4.70 & 4.61 & 1.18 & 10.00 & 5.14 & 4.79 & 1.19 \\
\hline 11.00 & 5.37 & 5.08 & 1.06 & 11.00 & 5.39 & 4.94 & 1.07 \\
\hline 12.00 & 4.70 & 4.38 & 1.03 & 12.00 & 5.50 & 5.11 & 1.03 \\
\hline 13.00 & 5.27 & 4.55 & 1.06 & 13.00 & 5.32 & 4.91 & 1.07 \\
\hline 14.00 & 4.83 & 4.70 & 1.18 & 14.00 & 5.32 & 4.91 & 1.19 \\
\hline 15.00 & 4.44 & 4.32 & 1.45 & 15.00 & 5.14 & 4.65 & 1.46 \\
\hline 16.00 & 5.16 & 4.83 & 2.05 & 16.00 & 4.83 & 4.32 & 2.07 \\
\hline 17.00 & 4.29 & 3.97 & 3.97 & 17.00 & 4.25 & 3.81 & 4.02 \\
\hline \multicolumn{4}{|c|}{$\begin{array}{l}\text { Date: } 21^{\text {st }} \text { November, } 2012 . \\
\text { Time/hrlnI } I_{R} \operatorname{lnI}_{B} \quad \text { air mass, } m\end{array}$} & \multicolumn{4}{|c|}{$\begin{array}{c}\text { Date: } 23^{\text {rd }} \text { November, } 2012 . \\
\text { Time/hrlnI } I_{R} \operatorname{lnI}_{B} \quad \text { air mass, } m\end{array}$} \\
\hline 08.00 & 4.50 & 4.25 & 2.06 & 08.00 & 4.01 & 3.56 & 2.07 \\
\hline 09.00 & 4.09 & 3.22 & 1.46 & 09.00 & 4.79 & 4.25 & 1.46 \\
\hline 10.00 & 5.11 & 4.65 & 1.19 & 10.00 & 5.27 & 4.44 & 1.19 \\
\hline 11.00 & 5.32 & 4.98 & 1.06 & 11.00 & 5.32 & 4.79 & 1.07 \\
\hline 12.00 & 5.37 & 5.16 & 1.03 & 12.00 & 5.65 & 5.19 & 1.03 \\
\hline 13.00 & 5.44 & 5.01 & 1.06 & 13.00 & 5.50 & 5.16 & 1.07 \\
\hline 14.00 & 5.44 & 5.01 & 1.19 & 14.00 & 5.39 & 4.94 & 1.19 \\
\hline 15.00 & 5.14 & 4.70 & 1.46 & 15.00 & 5.27 & 4.79 & 1.46 \\
\hline 16.00 & 4.70 & 4.38 & 2.06 & 16.00 & 4.94 & 4.44 & 2.07 \\
\hline 17.00 & 4.25 & 3.91 & 4.00 & 17.00 & 4.61 & 4.25 & 4.05 \\
\hline
\end{tabular}

Table 1: Natural logarithms for solar intensities and Air mass

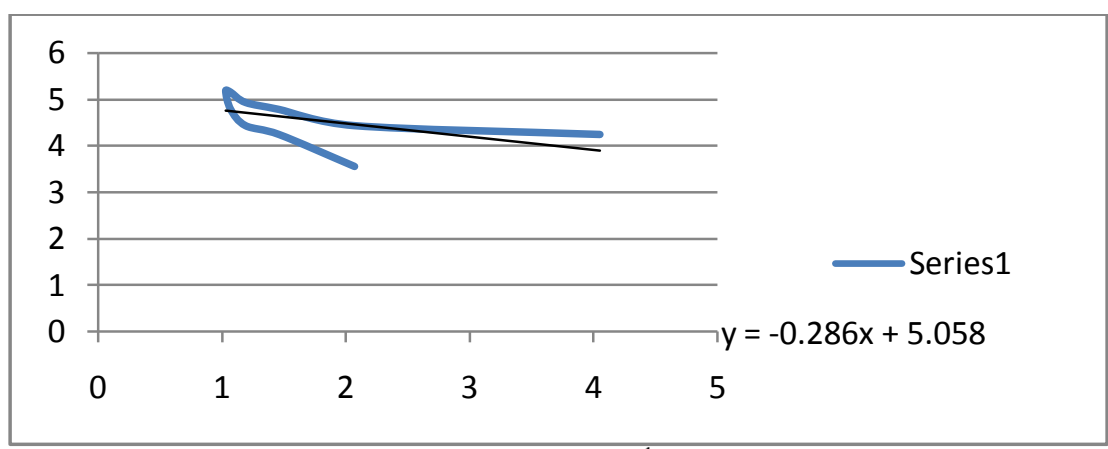

Figure 1: $\ln I_{R}$ against $m$ for $20^{\text {th }}$ November, 2012.

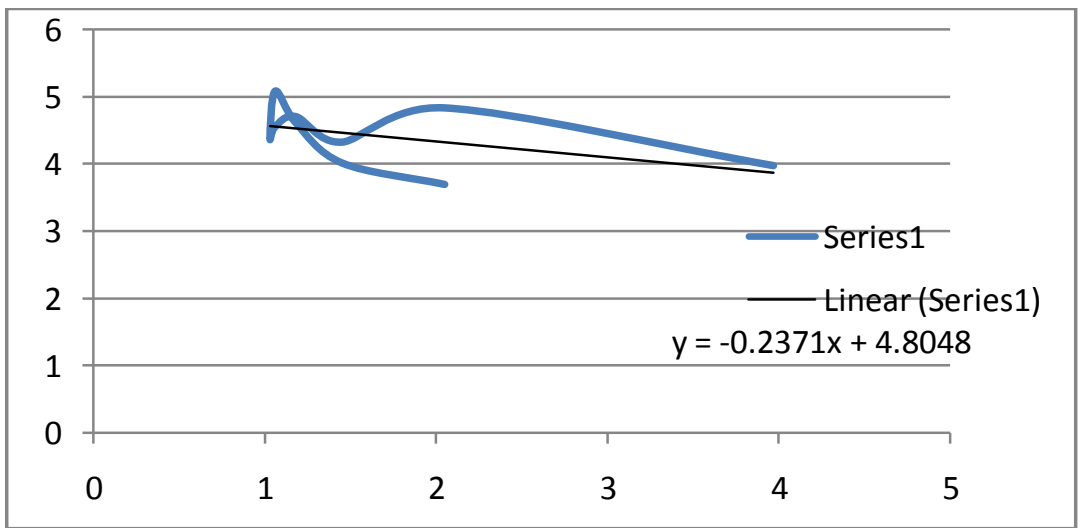

Figure 2: $\ln \mathrm{I}_{\mathrm{B}}$ against $\mathrm{m}$ for $20^{\text {th }}$ November, 2012. 


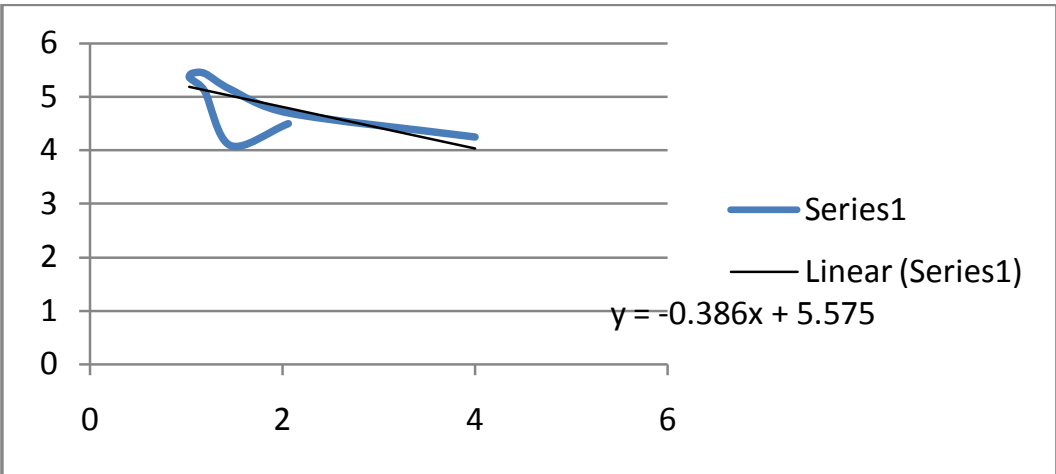

Figure 3: $\ln \mathrm{I}_{\mathrm{R}}$ against $\mathrm{m}$ for $21^{\mathrm{st}}$ November, 2012.

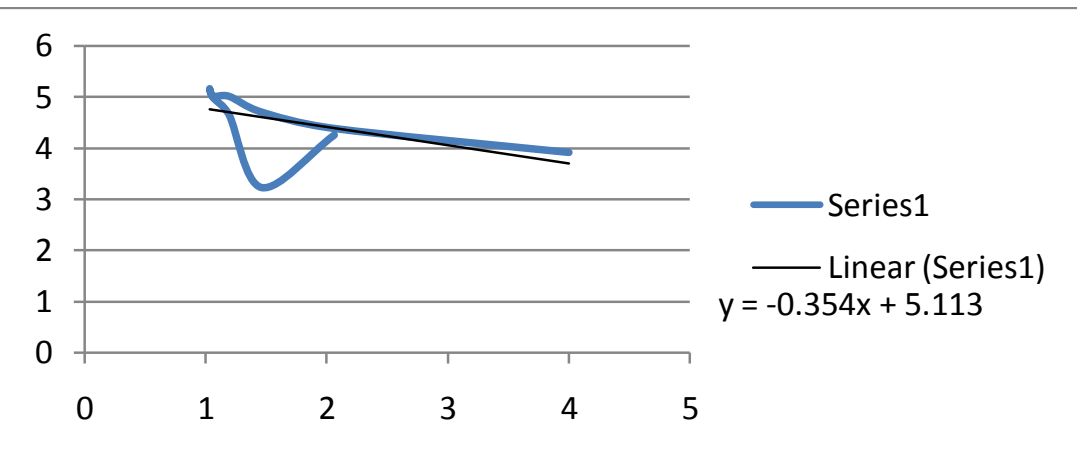

Figure 4: $\ln \mathrm{I}_{\mathrm{B}}$ against $\mathrm{m}$ for $21^{\mathrm{st}}$ November, 2012.

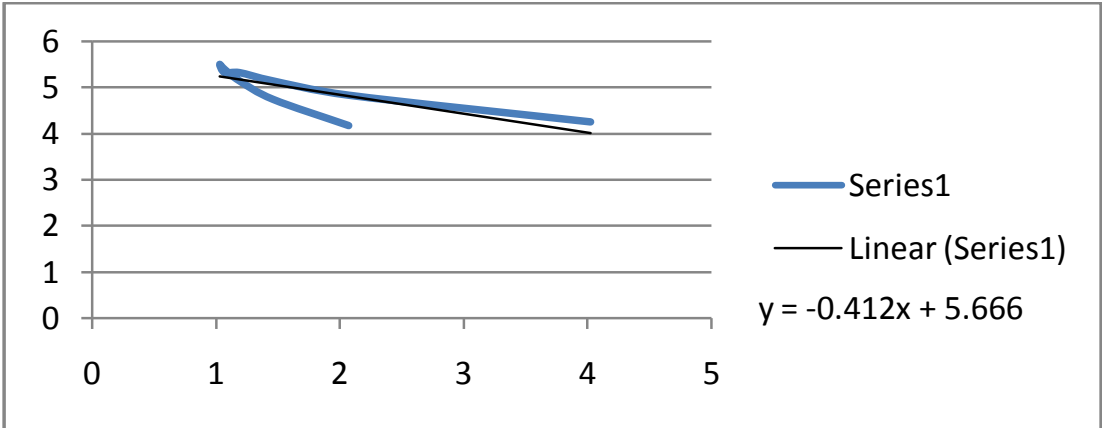

Figure 5: $\ln \mathrm{R}_{\mathrm{R}}$ against $\mathrm{m}$ for $22^{\text {nd }}$ November, 2012.

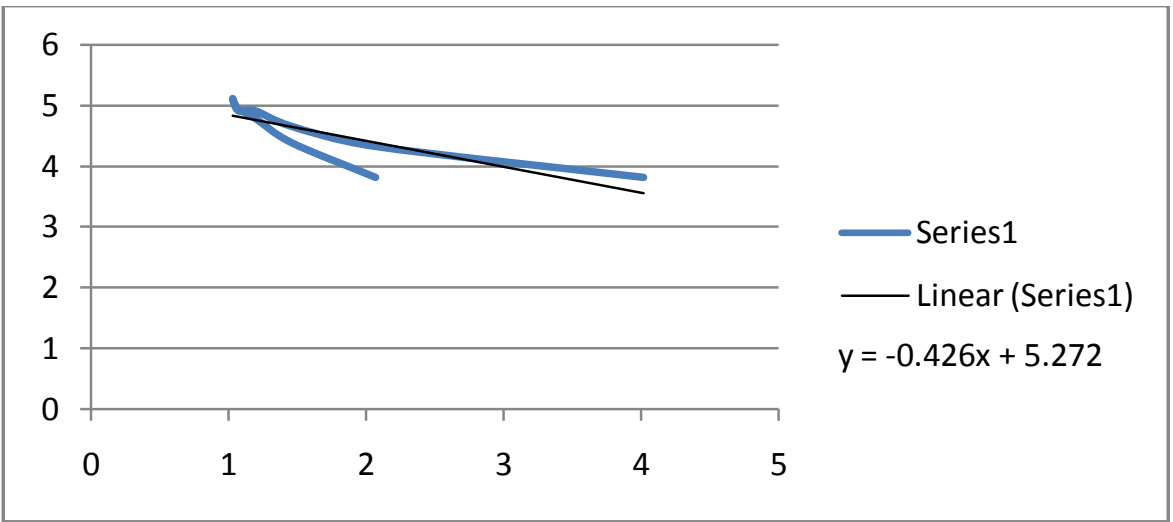

Figure 6: $\ln \mathrm{I}_{\mathrm{B}}$ against $\mathrm{m}$ for $22^{\text {nd }}$ November, 2012. 


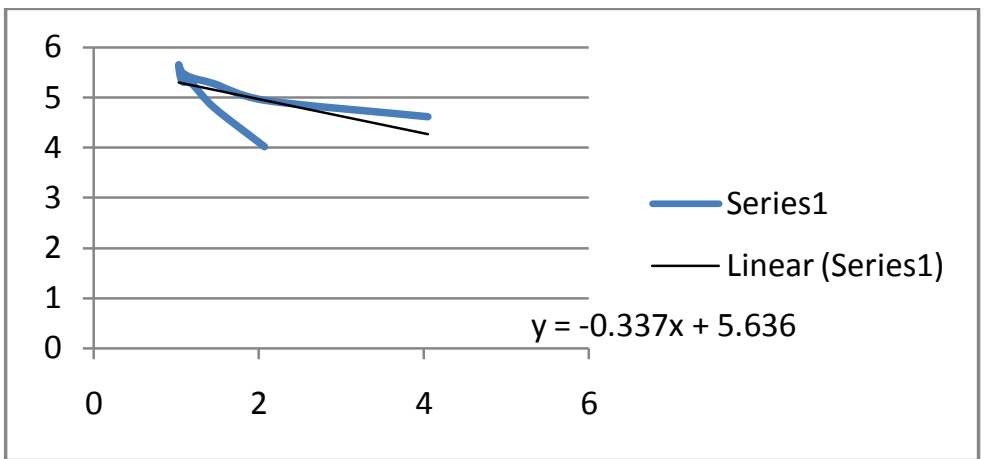

Figure 7: $\ln \mathrm{I}_{\mathrm{R}}$ against $\mathrm{m}$ for $23^{\text {rd }}$ November, 2012.

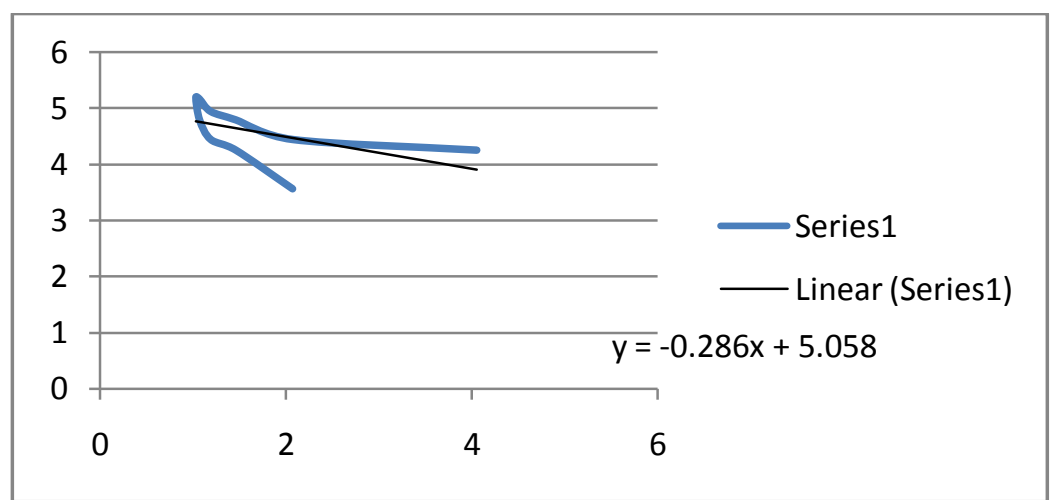

Figure 8: $\ln \mathrm{I}_{\mathrm{B}}$ against $\mathrm{m}$ for $23^{\text {rd }}$ November, 2012.

Water vapour content for the $20^{\text {th }}$ November, $\mathrm{U}=(0.2863 / 0.2371)^{2}=1.458 \mathrm{Kg} / \mathrm{m}^{2}$.

For the $21^{\text {st }}$ November, $\mathrm{U}=(0.3861 / 0.3540)^{2}=1.189 \mathrm{Kg} / \mathrm{m}^{2}$

For the $21^{\text {st }}$ November, $\mathrm{U}=(0.4129 / 0.4265)^{2}=0.937 \mathrm{Kg} / \mathrm{m}^{2}$

For the $21^{\text {st }}$ November, $\mathrm{U}=(0.3370 / 0.2863)^{2}=1.386 \mathrm{Kg} / \mathrm{m}^{2}$.

Average water vapour content is:

$$
1.458+1.189+0.937+1.386 / 4=1.243 \mathrm{Kg} / \mathrm{m}^{2} .
$$

\section{Discussion Of Results}

The atmospheric water vapour content was generally decreasing for the period under consideration. Probably, water vapour content may continue to decrease until when the atmosphere contains little or no water vapour as a result of gradual predominance of cool, dry north-eastern trade wind blowing over the study area in the harmattanperiodwhich extends from November to early March of the subsequent year. The values obtained for the water vapour was found to be in agreement with the relative humidity values collated at the Nigerian meteorological agency, located in Sokoto.

\section{Conclusion}

Measurement total water vapour content of the atmosphere for sokoto area using solar radiation intensity measurements was found to be in agreement with the relative humidity data obtained from NIMET, Sokoto station.

\section{References}

[1] Arthur, N.S and Alan, H.S (1997): Geography and man's environment, JohnWiley \& sons Inc, 9-11.

[2] Elmer, U.(2001): Green house effect and atmospheric absorption, MPI for chemistry, Mainz.

[3] Garg, H.P (1982): Treatise on Solar energy, Volume 1, Wiley inter science publication, Chichester.

[4] Houghton, J.T: The physics of atmospheres $2^{\text {nd }}$ edition, chapter 2

[5] Idemudia, G.(1998): Temporal variations in optical depth: determination using sunphotometry, Nigerian Journal of renewable en ergy, Vol. 6; no.1 and 2,48-51.

[6] John, W.T and Anthony, D.W (1986): Renewable energy resources, E \& F.NSpon; chapmann and hall, London, 66,70-72,77-78.

[7] McGraw Hill (1997): Encyclopaedia of Science \& Technology, Vol.2; $8^{\text {th }}$ edition, U.S.A, 566-568.

[8] Ruediger, L.(2001): Atmospheric water vapour content, MPI Mainz.

[9] Susanne, N.(2001): Concentration, how humid is air, MPI for Chemistry Mainz. 